\title{
Visible light-driven photophysics and photochemistry of water-soluble metalloporphyrins
}

Ottó Horváth, ${ }^{\mathrm{a}^{*}}$ Zsolt Valicsek, ${ }^{\mathrm{a}}$ Melinda A. Fodor, ${ }^{\mathrm{a}}$ Máté M. Major, ${ }^{\mathrm{a}}$ Muhammad Imran, ${ }^{\mathrm{a}}$ Günter Grampp, ${ }^{\mathrm{b}}$ Alexander Wankmüller ${ }^{\mathrm{b}}$

a Department of General and Inorganic Chemistry, Institute of Chemistry, University of Pannonia, P.O.Box 158, 8201 Veszprém, Hungary,

${ }^{\mathrm{b}}$ Institute of Physical and Theoretical Chemistry, Graz University of Technology, 8010 Graz, Stremayrgasse 9., Austria otto@mk.uni-pannon.hu

\section{Contents}

1. Introduction. .00

2. Photophysics and photoredox chemistry of water-soluble in-plane metalloporphyrins.....00

2.1 Photophysics and photoredox chemistry of cationic manganese(III) and cobalt(III)

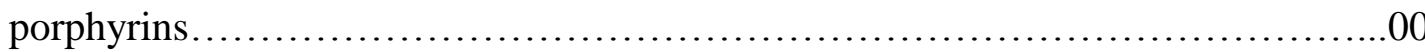

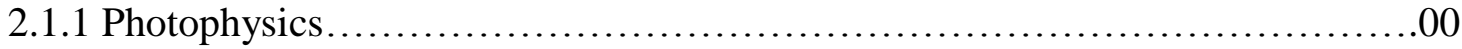

2.1.2 Photochemistry....................................................... 00

2.2 Photophysics and photoredox chemistry of a cationic nickel(II) porphyrin............00

2.2.1 Photophysics......................................................... 00

2.2.2 Photochemistry........................................................ 00

3. Photophysics and photochemistry of water-soluble out-of-plane lanthanide(III)

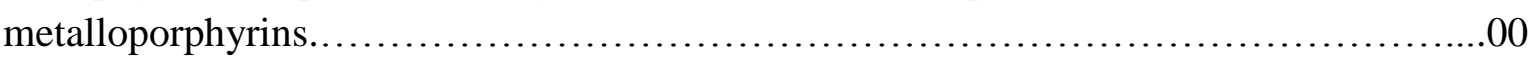

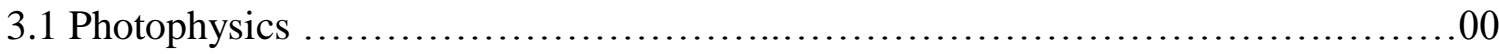

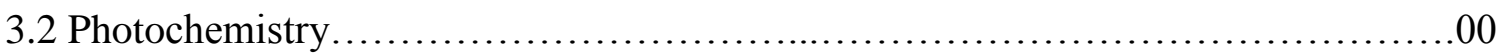

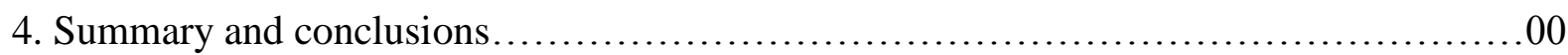

Acknowledgment.............................................................. 00

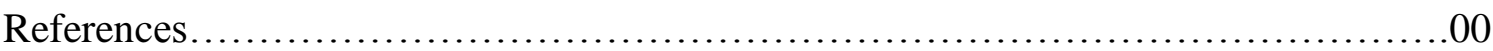

\begin{abstract}
Metal ions can form normal (in-plane) metalloporphyrins, fitting into the central hole of the porphyrin ring, or several of them are located out of the ligand plane, resulting in sittingatop (SAT) complexes. Kinetically inert water-soluble complexes of $\mathrm{Mn}$ (III), Co(III), and $\mathrm{Ni}$ (II) with 5,10,15,20-tetrakis(1-methylpyridinium-4-yl)porphyrin display a weak, short-lived fluorescence. This can be affected by elongation of the alkyl substituent and using micellar environment in the case of $\mathrm{Mn}$ (III) porphyrins. In the presence of a suitable electron donor (triethanolamine, TEOA) and acceptor (methylviologen, $\mathrm{MV}^{2+}$ ), these metalloporphyrins proved to be efficient photocatalysts transferring electrons between the ground-state donor and acceptor via outer-sphere mechanism. In these systems triplet excited-state Mn(III) and
\end{abstract}


Co(III) porphyrins are dynamically quenched with TEOA. The $\mathrm{Mn}$ (II) and $\mathrm{Co}$ (II) complexes formed in this way need also photoexcitation for the transfer of electron to the ground-state acceptor. However, the triplet excited state of $\mathrm{Ni}(\mathrm{II}) \mathrm{TMPyP}^{4+}$ cannot be dynamically quenched with TEOA. Instead, this electron donor forms an associate with $\mathrm{Ni}(\mathrm{II}) \mathrm{TMPyP}^{4+}$ in a ground state equilibrium. The lifetime of the triplet excited state of this species is much longer than that of the nickel(II) porphyrin alone, and it can undergo an efficient dynamic oxidative quenching with $\mathrm{MV}^{2+}$. Thus, a one-step electron transfer can be realized between the electron donor and acceptor, generating $\mathrm{MV}^{\bullet+}$, which can be utilized for hydrogen generation from water.

Lanthanide(III) porphyrins are of typical SAT complexes, the photophysical and -chemical features of which can be tuned by the size of the metal center. Anionic, early lanthanide(III) mono- and bisporphyrin complexes exhibit very similar photoinduced properties as a consequence of a special type of aggregation, through the peripheral substituents. The rather slow formation of complexes and transformation between the mono- and bisporphyrins can be accelerated by the irradiation of the system. These by-processes play considerable roles beside the photoredox degradation and demetalation. Depending on the wavelength of irradiation, two types of photoproducts can appear: during the photolysis at the Soret-band, a radical type intermediate can be observed, which disappears in dark. However, irradiation at the Q-bands, generates the formation of a new, stable photoproduct.

Keywords: metalloporphyrins; photochemistry; out-of-plane compexes; in-plane complexes; photocatalysis; lanthanide ions

\section{Introduction}

Metalloporphyrins display special spectral and coordination features [1, 2]. Their advantageous photoinduced properties can also be exploited in various photocatalytic procedures [3, 4]. Water-soluble derivatives can be utilized in environmentally benign systems not containing organic solvents.

Kinetically inert in-plain metalloporphyrins, in which the metal center is coplanarly located in the cavity of the ligand, may offer promising possibilities for realization of photocatalytic systems based on outer-sphere electron transfer [5]. The so-called hyper-porphyrins can be particularly interesting in this respect, due to their distorted structure, which may increase the (photo)redox reactivity of these complexes. In these complexes the metal center is smaller than the ligand cavity, hence it shrinks the porphyrin ring, resulting in a saddle or ruffled distortion.

Metal ions can be located out of the ligand plane too, resulting in kinetically labile out-ofplane (OOP or sitting-atop=SAT) complexes with dome-distorted structure, displaying typical photophysical and photochemical properties $[3,6]$. Besides, the OOP position promotes the formation of bis- or oligoporphyrins [7]. Lanthanide(III) complexes can be typical examples of metallo-oligoporphyrins, in which the $\pi-\pi$ interaction depends on the distance between the 
macrocycles, strongly influenced by the size of the metal center [8, 9]. Therefore, lanthanide(III) ions are good candidates for fine tuning of the out-of-plane distances, due to the lanthanide contraction.

The typical in-plane metalloporphyrins show blueshifts in the Soret-range compared to the corresponding free-base porphyrins because the atomic orbitals of their metal center covalently bonded in the plane can overlap more strongly with the occupied molecular orbitals (the highest in energy is the HOMO) of the ligand, resulting in a stronger reduction in energy; while the unoccupied MOs (the lowest is the LUMO) do not change. Accordingly, the energy gaps between the excited and ground states increase.

In the out-of-plane complexes, the atomic orbitals of the more weakly bonded metal ions may slightly influence the unoccupied MOs and lesser the occupied ones, resulting in the decrease of the energy gaps, i.e. the increase of the corresponding wavelengths.

The aim of this review is to exemplify the considerable difference between the photoinduced features of the kinetically inert in-plane and the labile sitting-atop (SAT) or out-of-plane (OOP) complexes, due to their fundamental constructional deviation. Fig. 1 shows the structures of the anionic and cationic porphyrins involved in this work. In the case of the cationic porphyrins, additionally (beside the methyl) hexyl and dodecyl derivatives were also investigated.

Fig. 1. Structures of anionic and cationic porphyrins: $\mathrm{H}_{2} \mathrm{TSPP}^{4-}=5,10,15,20$-tetrakis(4sulfonatophenyl)porphyrin, $\mathrm{H}_{2} \mathrm{TMPyP}^{4+}=5,10,15$,20-tetrakis(1-methyl-4pyridinium)porphyrin.

\section{Photophysics and photoredox chemistry of water-soluble in-plane metalloporphyrins}

In the case of most of the in-plane metalloporphyrins the size of the metal center corresponds to that of the ligand cavity, thus it is located in the porphyrin plane and does not distort it. However, if the ionic radius $\left(r_{i}\right)$ of the central metal is significantly smaller than the core of the porphyrin, i.e. $r_{i}<70 \mathrm{pm}$, it shrinks the ligand and, hence, causes its distortion. The type of such a distortion may be saddle, wave or ruffled. This structural change, compared to the normal in-plane metalloporphyrins, considerably modifies the visible absorption spectrum of these complexes, especially in the range of the Soret-bands. While the Soret-bands of most of the in-plane metalloporphyrins display blue shifts compared to those of the corresponding free bases, due to electronic interactions between the ligand and the metal center, the distorted ones exhibit red shifts in this respect. Thus, as a distinction, since the spectra of these complexes could not be interpreted by the 4 MO theory of Gouterman, they have been classified as hyper-porphyrins $[10,11]$. The porphyrin complexes of manganese(III) $\left(r_{i}=58\right.$ pm, low-spin), cobalt(III) ( $r_{i}=55 \mathrm{pm}$, low-spin), and nickel(II) $\left(r_{i}=63 \mathrm{pm}\right.$, low-spin) [12] belong to this group [13]. Some photophysical and photoredox properties of cationic porphyrin complexes of these metal ions will be discussed in the following sections. 


\subsection{Photophysics and photoredox chemistry of cationic manganese(III) and cobalt(III)}

porphyrins

\subsubsection{Photophysics}

Some photophysical properties of cationic manganese(III) and cobalt(III) porphyrins, Mn(III)TMPyP ${ }^{5+}$ and Co(III)TMPyP ${ }^{5+}$ were already studied [14, 15] earlier. It was generally accepted that the highly distorted porphyrin complexes with diamagnetic metal center do not display appreciable fluorescence at room temperature. Accordingly, porphyrin complexes of low-spin $\mathrm{Mn}$ (III) and Co(III) were considered to be very weakly fluorescent. However, current investigations using a more sensitive equipment indicated that both $\mathrm{Mn}(\mathrm{III}) \mathrm{TMPyP} \mathrm{P}^{5+}$ and Co(III)TMPyP ${ }^{5+}$ display a characteristic fluorescence in the 600-750-nm range (Fig 2), which is more than an order of magnitude weaker $\left(\Phi_{\mathrm{fl}}=1.1 \times 10^{-4}\right.$ and $1.4 \times 10^{-3}$ for the $\mathrm{Mn}$ (III) and $\mathrm{Co}(\mathrm{III})$ complexes, respectively[16, 17]) than that exhibited by the corresponding free base (0.047 [18], 0.030 [19]). The shorter emission lifetimes of these complexes are also in accordance with this tendency caused by both electronic and steric interactions between the metal center and the ligand in these hyper-porphyrins.

Fig 2. Fluorescence spectra of $\mathrm{Mn}(\mathrm{III}) \mathrm{TMPyP}^{5+}, \mathrm{Co}(\mathrm{III}) \mathrm{TMPyP}^{5+}$ and $\mathrm{H}_{2} \mathrm{TMPyP}^{4+}$ obtained by excitation at the Soret-bands. Adapted from refs $[16,17]$.

The fluorescence bands shown in Fig 2 can be assigned as $S_{1} \rightarrow S_{0}$ transitions (with various vibrational states). The fluorescence bands of metalloporphyrins (both for in-plane and for out-of-plane complexes) are blue-shifted and less intense compared to those of the corresponding free-base porphyrin. The same spectra were obtained at Q-band excitations, confirming that they are the results of $S_{1} \rightarrow S_{0}$ transition.

Elongation of the alkyl chain on the pyridinium substituent (from methyl to hexyl or dodecyl) in the case of the cationic manganese(III) porphyrins resulted in a significant (about an order of magnitude) increase in the fluorescence quantum yield (to $1.4 \times 10^{-3}[16]$ ), while for the corresponding free bases just a moderate decrease within the same order magnitude was observed [20].This phenomenon may be attributed to the stronger electron-donating property of the longer hydrocarbon chains. In the solution of a cationic surfactant (cetyltrimethyl ammonium) providing a micelle:Mn(III)-porphyrin ratio > 1, the fluorescence lifetime decreased upon increasing the length of the alkyl chain (3.40 ns, $3.03 \mathrm{~ns}$, and $2.30 \mathrm{~ns}$ for methyl, hexyl, and dodecyl deriavtives, respectively). This tendency, which is just the opposite of the change observed in the homogeneous aqueous system, can be attributed the increasing hydrophobic interaction between the alkyl chains of the surfactant in the micelles and those of the substituents on the porphyrins.

\subsubsection{Photochemistry}

Both Mn(III)TMPyP ${ }^{5+}$ and Co(III)TMPyP ${ }^{5+}$ were applied in various photocatalytic systems. The cobalt(III) complex proved to be more efficient in oxidation of the sulfide content of a wastewater to sulfate, at Soret-band excitation [21]. It could also be used for oxidative splitting of DNA in the presence of suitable electron acceptors [22]. Mn(III)TMPyP ${ }^{5+}$ was 
utilized in photocatalytic oxygenations of various hetero-bicyclic organic compounds such as furan and thiophene derivatives $[23,24]$. In the latter cases, the corresponding manganese(V)oxo species was suggested to play the key role in the oxidation process.

While the mechanism of the photocatalytic oxidations and oxygenations has not been investigated in detail, photoreductive catalyses based on these metalloporphyrins were more thoroughly investigated.

Utilizing ethylenediaminetetraacetate (EDTA) or triethanolamine (TEOA) as sacrificial electron donors and methylviologen $\left(\mathrm{MV}^{2+}\right)$ as an acceptor, photocatalytic systems were realized for generation of $\mathrm{MV}^{\bullet+}$, using cationic manganese(III) $[3,25,26]$ and cobalt(III) [17] porphyrins. Current investigations indicated that application of a longer alkyl chain on the pyridinium substituent increases the efficiency of the $\mathrm{MV}^{\bullet+}$ accumulation. Thus, e.g., the corresponding hexyl derivative (Mn(III)THPyP ${ }^{5+}$ ) proved to be significantly effective than the well-known methylated species (Mn(III)TMPyP ${ }^{5+}$ ) [16].

However, although the photocatalytic formation of $\mathrm{MV}^{\bullet+}$ of characteristic bands at 398 and $605 \mathrm{~nm}$ [27] is relatively fast (Fig 3) and the system persisted for several hours, the decomposition of the catalyst is more significant than in the case of $\mathrm{Mn}(\mathrm{III}) \mathrm{TMPyP}^{5+}$. This phenomenon is probably the consequence of the increased electron donating character of the substituent promoting the ligand-to-metal charge transfer, irreversibly oxidizing the porphyrin ring. Application of cationic micelles moderately increased the stability [16].

Fig 3. Spectral change in the system initially containing $5 \times 10^{-6} \mathrm{M} \mathrm{Mn}(\mathrm{III}) \mathrm{THPyP}^{5+}, 5 \times 10^{-4} \mathrm{M}$ TEOA and $2 \times 10^{-3} \mathrm{M} \mathrm{MV}^{2+}$ during the irradiation at 0,10 and $30 \mathrm{~s}\left(\lambda_{\mathrm{ir}}=465 \mathrm{~nm}, \ell=1 \mathrm{~cm}\right)$. Adapted from ref [16].

Both the reduction of the metal center of the catalyst (with a sacrificial electron donor) and the oxidation of its reduced form (with an appropriate acceptor) needed photoexcitation. The same behavior was displayed by the corresponding cobalt(III) complex [17], and thus the two steps can be described by the following general equations.

$$
\begin{aligned}
& \mathrm{M}(\mathrm{III}) \mathrm{TMPyP}^{5+}+\mathrm{TEOA}+\mathrm{h} v \rightarrow \mathrm{M}(\mathrm{II}) \mathrm{TMPyP}^{4+}+\mathrm{TEOA}_{\mathrm{ox}} \\
& \mathrm{M}(\mathrm{II}) \mathrm{TMPyP}^{4+}+\mathrm{MV}^{2+}+\mathrm{h} v \rightarrow \mathrm{M}(\mathrm{III}) \mathrm{TMPyP}^{5+}+\mathrm{MV}^{\bullet+}
\end{aligned}
$$

The quantum yields for the formation $\mathrm{MV}^{\bullet+}$ at Soret-excitation are comparable for the systems based on these two metalloporphyrins $(\Phi=1.5-2.6 \%)$, and they may be considerable for the application of these systems for hydrogen generation from water.

. The Soret-band of the complex with the reduced metal center (M(II)) formed in reaction (1) is blueshifted compared to that of the M(III) porphyrin for both manganese $[25,26]$ and cobalt [17, 28], due to the larger ionic radii of the previous ones (89 pm for $\mathrm{Mn}$ (II) and $75 \mathrm{pm}$ for $\mathrm{Co}(\mathrm{II})$ [12]). The singlet excited states of the cationic $\mathrm{Mn}$ (III) and $\mathrm{Co}$ (III) porphyrins are very short-lived $\left(\tau_{\mathrm{fl}}<7 \mathrm{~ns}\right)$ for an efficient quenching with TEOA (in Eq. 1). Their triplet states (Fig. 4), however, proved to be long-lived enough ( $\tau=53 \mu$ s for Mn(III)TMPyP ${ }^{4+}$ and $\tau$ 
$=102 \mu \mathrm{s}$ for $\left.\mathrm{Co}(\mathrm{III}) \mathrm{TMPyP}^{4+}\right)$, hence they were dynamically quenched with TEOA $\left(\mathrm{k}_{\mathrm{q}}=\right.$ $6.7 \times 10^{6} \mathrm{M}^{-1} \mathrm{~s}^{-1}$ and $\left.4.7 \times 10^{6} \mathrm{M}^{-1} \mathrm{~s}^{-1}\right)[16,17]$.

Fig 4. Transient absorption spectra of triplet-states of $\mathrm{Mn}(\mathrm{III}) \mathrm{TMPyP}^{4+}(\mathbf{\square})$ and $\mathrm{Co}(\mathrm{III}) \mathrm{TMPyP}^{4+}(\bullet)$. Adapted from refs $[16,17]$.

A similar situation must be valid for the reactions between $\mathrm{MV}^{2+}$ and the triplet excited state of the corresponding reduced ( $\mathrm{Mn}(\mathrm{II})$ and $\mathrm{Co}(\mathrm{II})$ ) porphyrins (Eq. 2).

Cationic porphyrins of both manganese(III) and cobalt(III) proved to be function in the catalytic cycle containing TEOA and $\mathrm{MV}^{2+}$ in the same way, which is summarized in Scheme 1.

Scheme 1. Photocatalytic cycle based on cationic manganese(III) or cobalt(III) porphyrins.

\subsection{Photophysics and photoredox chemistry of a cationic nickel(II) porphyrin}

\subsubsection{Photophysics}

Deviating from the corresponding manganese(III) and cobalt(III) porphyrins, Ni(II)TMPyP ${ }^{4+}$ displays a double Soret-band in aqueous solution (see in Fig 5), due to its two spin states in equilibrium [29]. The low-spin metal center is characterized with a square planar coordination sphere, while the high-spin $\mathrm{Ni}$ (II) with an octahedral one. The Soret-band of the latter species appears at $449 \mathrm{~nm}$, while that of the low-spin complex can be found at $420 \mathrm{~nm}$ (very close to the Soret-band of the free-base ligand). Similarly to the corresponding cationic $\mathrm{Mn}(\mathrm{III})$ and $\mathrm{Co}(\mathrm{III})$ metalloporphyrins, also $\mathrm{Ni}(\mathrm{II}) \mathrm{TMPyP}^{4+}$ displays a characteristic fluorescence upon excitation at the Soret-bands [30]. Interestingly, the shape and the position of the emission spectra do not significantly depend on the excitation wavelength, and they well agree with those of the Mn(III)TMPyP ${ }^{5+}$ and Co(III)TMPyP ${ }^{5+}$ complexes. This phenomenon suggests that the excited state from which the $\mathrm{S}_{1}$ fluorescence originates is the same in both cases, no matter which ground state (low-spin or high-spin) was excited. Nevertheless, the fluorescence lifetimes slightly deviate: $1.36 \mathrm{~ns}$ for the square planar and $1.19 \mathrm{~ns}$ for the octahedral complex. The quantum yield of the fluorescence $\left(\Phi_{\mathrm{fl}}=2.0 \times 10^{-3}\right)$ is in the same order of magnitude as that of $\mathrm{Co}$ (III)TMPyP ${ }^{5+}\left(9.9 \times 10^{-4}\right)$. The higher value can be attributed to the larger ionic radius causing smaller distortion (shrinkage) of the porphyrin ring as also indicated by the location (less redshift) of the Soret-bands.

\subsubsection{Photochemistry}

Similarly to the cationic manganese(III) and cobalt(III) porphyrins, a photocatalytic system was realized with $\mathrm{Ni}(\mathrm{II}) \mathrm{TMPyP}^{4+}$ too in presence of $\mathrm{MV}^{2+}$ and TEOA in argon-saturated aqueous solutions at room temperature (Fig. 5). However, in this case the spectral behavior of the system is significantly different from that observed with the corresponding $\mathrm{Mn}$ (III) and $\mathrm{Co}$ (III) porphyrins under similar conditions. In those systems two photochemical steps were involved in the photocatalytic cycle producing methylviologen [3, 16, 17]. During the irradiation of the nickel(II) porphyrin system, however, the accumulation of $\mathrm{MV}^{\bullet+}$ was not 
accompanied by any change in the spectrum of the photocatalyst (Fig 5). The quantum yield for the formation of $\mathrm{MV}^{\bullet+}$ proved to be less than those for the $\mathrm{Mn}$ (III) and $\mathrm{Co}$ (III) porphyrins $(\Phi=0.011$ at $\mathrm{pH} 8.4)$. At $\mathrm{pH} 10$ it increased to 0.013 .

Fig 5. Spectral change of the solution initially containing $1.0 \times 10^{-5} \mathrm{M} \mathrm{Ni}(\mathrm{II}) \mathrm{TMPyP}^{4+}, 5 \times 10^{-4}$ $\mathrm{M}$ TEOA and $2 \times 10^{-3} \mathrm{M} \mathrm{MV}^{2+}$ during the irradiation at $0,24,84,204$ and $600 \mathrm{~s}\left(\lambda_{\text {ir }}=463 \mathrm{~nm}\right.$, $\ell=1 \mathrm{~cm})$. Adapted from ref [30].

One can expect the formation of the highly instable $\mathrm{Ni}(\mathrm{I})$ porphyrin (or reduced nickel porphyrin), which relays the electron in a fast thermal process. Such a reduced complex could only be formed via triplet excited state quenched by TEOA as in the cases of the manganese(III) and cobalt(III) porphyrins. In fact, time-resolved laser flash photolysis investigations confirmed the formation of triplet excited state of the Ni(II)TMPyP ${ }^{4+}$ photocatalyst (Fig 6) [30]. Interestingly, its lifetime $(6.31 \mu \mathrm{s})$ did not decrease upon addition of $1.0 \times 10^{-3} \mathrm{M}$ TEOA, moreover it increased to $31.6 \mu \mathrm{s}$. This phenomenon indicated that TEOA connects to the ground-state complex, and the excited triplet state of this associate is much longer than that of the nickel(II) porphyrin alone. Additionally, the triplet state of this associate could be efficiently quenched with $\mathrm{MV}^{2+}$ (Fig 6, inset). The rate constant for this process was determined to be $\mathrm{k}_{\mathrm{q}}=9.9 \times 10^{6} \mathrm{~s}^{-1} \mathrm{M}^{-1}$.

Fig 6. Transient spectrum of triplet excited Ni(II)TMPyP ${ }^{4+}$ recorded 510 ns after a 355-nm laser pulse of $5 \mathrm{~ns}$ duration. Inset: quenching of triplet $\mathrm{Ni}(\mathrm{II}) \mathrm{TMPyP}^{4+}$ with $\mathrm{MV}^{2+}$ in the presence of $1.0 \times 10^{-3} \mathrm{M}$ TEOA. Adapted from ref [30].

Accordingly, deviating from the corresponding Mn(III) and Co(III) system, in the case of the nickel(II) porphyrin the electron transfer from TEOA to $\mathrm{MV}^{2+}$ takes place directly in one step, due to the ground-state association of the electron donor and the photocatalyst (Eqs. 5, 6).

$$
\begin{gathered}
\mathrm{Ni}(\mathrm{II}) \mathrm{TMPyP}^{4+}+\mathrm{TEOA} \leftrightarrow \mathrm{Ni}(\mathrm{II}) \mathrm{TMPyP}^{4+}-\mathrm{TEOA} \\
\mathrm{Ni}(\mathrm{II}) \mathrm{TMPyP}^{4+}-\mathrm{TEOA}+\mathrm{MV}^{2+}+\mathrm{h} v \rightarrow \mathrm{Ni}(\mathrm{II}) \mathrm{TMPyP}^{4+}+\mathrm{MV}^{\bullet+}+\mathrm{TEOA}_{\mathrm{ox}}
\end{gathered}
$$

On the basis of this mechanism, the photocatalyst in this case is practically a special sensitizer which immediately transmits its excitation energy to the electron donor, promoting the direct charge transfer towards the acceptor.

\section{Photophysics and photochemistry of water-soluble out-of-plane lanthanide(III) porphyrins}

Larger-sized metal ions are not able to coplanarly fit into the cavity of the porphyrin ring, hence they form OOP or SAT complexes with dome-distorted structure, thermodynamic instability, kinetic lability, typical photophysical features, and photochemical reactivity [3, 11]. Lanthanide(III) ions offer good opportunities for fine tuning of the out-of-plane distance, utilizing the monotonous decrease of their radii from $116 \mathrm{pm}$ to $98 \mathrm{pm}$ (at coordination number 8) upon increasing atomic numbers [12]. Additionally, they prone to form bis- or 
oligoporphyrins $[31,32,33]$, the photoinduced properties of which strongly depend on the $\pi-\pi$ interaction between the macrocycles. Notably, porphyrins are able to efficiently sensitize the near-infrared luminescence of lanthanide ions, which can be widely applied from telecommunication to biomedical optical imaging [34, 35]. Besides, lanthanide(III) porphyrins may be applied for photocatalytic hydrogen production from water because their reduced metal centers $(\mathrm{Ln}(\mathrm{II}))$ formed in photoinduced LMCT processes (typical for OOP complexes $[36,37]$ ) have considerably high negative redox potentials (except for europium)[38]. In this section, we survey the photophysical and primary photochemical properties of the complexes between a water-soluble, anionic porphyrin, the 5,10,15,20tetrakis(4-sulfonatophenyl)porphyrin $\left(\mathrm{H}_{2} \mathrm{TSPP}^{4-}\right)$ and three early lanthanide(III) ions ( $\mathrm{Ln}=$ $\mathrm{La}, \mathrm{Ce}, \mathrm{Nd})$.

\subsection{Photophysics}

Lanthanide(III) ions are hard Lewis acids, therefore their insertion into the coordination cavity of the tetradentate, $\mathrm{N}$-donor porphyrin ligand is a very slow process in aqueous solution [9, 39]. It is partly the consequence of the strong $\mathrm{Ln}(\mathrm{III})-\mathrm{H}_{2} \mathrm{O}$ bond. Accordingly, a harder Odonor ligand, such as acetate, can hinder the coordination of the second porphyrin to the metal ion $[34,35,38,39]$. In the absence of acetate, bisporphyrin $\left(\operatorname{Ln}_{3} \mathrm{TSPP}_{2}{ }^{3-}\right)$ can form too, which has slightly redshifted and broadened absorption bands, compared to those of the monoporphyrin (Fig. 7).

Fig 7. Molar absorption spectra of lanthanum(III) mono- and bisporphyrin: a) in the Soretrange; b) in the Q-range. Adapted from ref [9].

Similarly to $\mathrm{La}^{\mathrm{III}} \mathrm{TSPP}^{3-}$ and $\mathrm{La}^{\mathrm{III}}{ }_{3} \mathrm{TSPP}_{2}{ }^{3-}$, the corresponding complexes of other lanthanide(III) ions, such as $\mathrm{Ce}(\mathrm{III})$ and $\mathrm{Nd}(\mathrm{III})$, display typical OOP absorption spectra [40, 41], with redshifted bands compared to those of the corresponding free base (Table 1).

Table 1. Characteristic data for the absorption, singlet-1 fluorescence and singlet-2 photochemistry (photolysis at the Soret-band) of the investigated lanthanide(III) mono- and bisporphyrins.

\begin{tabular}{|c|c|c|c|c|c|c|c|c|}
\hline complex & $\mathbf{H}_{2} \mathbf{T}$ & $\mathbf{S P P}^{4-}$ & LaTSPP $^{3-}$ & $\mathrm{La}_{3} \mathrm{TSPP}_{2}{ }^{3-}$ & CeTSPP $^{3}$ & $\mathrm{Ce}_{3} \mathrm{TSPP}_{2}{ }^{3-}$ & NdTSPP $^{3-}$ & $\mathrm{Nd}_{3} \mathrm{TSPP}_{2}{ }^{3-}$ \\
\hline $\mathbf{L n}^{3+}$ radius /pm & \multicolumn{2}{|c|}{-} & \multicolumn{2}{|c|}{116} & \multicolumn{2}{|c|}{114} & \multicolumn{2}{|c|}{111} \\
\hline$\lambda \mathbf{B}(\mathbf{0 , 0}) / \mathrm{nm}$ & & 13 & 421 & 423 & 421 & 422 & 421 & 422 \\
\hline$\varepsilon \mathrm{B}\left(\mathbf{0 , 0 )} / \mathbf{1 0}^{5} \mathrm{M}^{-1} \mathrm{~cm}^{-1}\right.$ & & 66 & 4.77 & 4.75 & 4.76 & 4.43 & 5.56 & 4.90 \\
\hline$\lambda Q(1,0) / n m$ & у 516 & x 579 & 555 & 557 & 555 & 557 & 555 & 557 \\
\hline$\varepsilon Q(1,0) / 10^{4} \mathbf{M}^{-1} \mathbf{c m}^{-1}$ & y 1.67 & $\mathrm{x} 0.67$ & 1.83 & 1.65 & 1.83 & 1.64 & 1.96 & 1.76 \\
\hline$\phi\left(\mathbf{S}_{1}\right.$-fluo $) / \mathbf{1 0}^{-2}$ & & 53 & 2.74 & 1.03 & 3.10 & 1.42 & 3.93 & 2.59 \\
\hline
\end{tabular}




\begin{tabular}{|c|c|c|c|c|c|c|c|}
\hline$\phi\left(\mathbf{S}_{1}-\right.$ fluo@B $) / 1^{-2}$ & 5.62 & 1.62 & 0.67 & 2.06 & 0.95 & 3.05 & 1.71 \\
\hline$\phi\left(\mathbf{I C ~ S}_{2}-\mathbf{S}_{1}\right)$ & 0.746 & 0.59 & 0.65 & 0.66 & 0.67 & 0.78 & 0.66 \\
\hline$\tau\left(\mathbf{S}_{1}\right) / \mathbf{n s}$ & 10.03 & 1.99 & 2.00 & 1.97 & 2.00 & 1.94 & 1.99 \\
\hline$k_{r}\left(S_{1}\right) / 10^{6} s^{-1}$ & 7.5 & 13.8 & 5.1 & 15.7 & 7.1 & 20.2 & 13.0 \\
\hline$k_{\mathrm{nr}}\left(\mathrm{S}_{1}\right) / 10^{7} \mathrm{~s}^{-1}$ & 9.2 & 48.9 & 49.5 & 49.2 & 50.5 & 49.4 & 48.8 \\
\hline $\begin{array}{c}\phi\left(\mathrm{S}_{2}-\text { photochem }\right)^{*} \\
/ 10^{-3}\end{array}$ & 0.006 & 0.76 & 1.51 & 1.37 & 1.98 & 0.81 & 2.25 \\
\hline redox $\%$ & $100 \%$ & $86 \%$ & $78 \%$ & $80 \%$ & $74 \%$ & $83 \%$ & $76 \%$ \\
\hline dissociation \% & - & $10 \%$ & $12 \%$ & $14 \%$ & $11 \%$ & $12 \%$ & $12 \%$ \\
\hline transformation \% & - & $4 \%$ & $10 \%$ & $6 \%$ & $15 \%$ & $5 \%$ & $12 \%$ \\
\hline ref. & {$[43]$} & & & & & & \\
\hline
\end{tabular}

${ }^{*}=\sim 10^{-6} \mathrm{M}$ porphyrin, $\sim 10^{-3} \mathrm{M}$ metal ion, $0.01 \mathrm{M}$ ionic strength adjustor.

These complexes display characteristic singlet-1 fluorescences, which are blueshifted, less intense and shorter-lived related to the free-base porphyrin (Fig. 8 and Table 1), due to the dome distortion.

Fig 8. Singlet-1 fluorescence spectra of lanthanum(III) mono- and bisporphyrin. Adapted from ref [9].

A paramagnetic metal ion can perturb the molecule orbitals of the macrocycle or can cause the disappearance of fluorescence by spin-orbit coupling only if it is in the ligand plane. Hence, the emission properties of the $\mathrm{Ce}$ (III) and $\mathrm{Nd}$ (III) porphyrins are very similar to those of the La(III) porphyrins [9, 40, 41]. Besides, the fluorescence of lanthanide(III) bisporphyrins is much like that of the monoporphyrins, only its quantum efficiency is slightly lower, probably due to the weak $\pi-\pi$ interactions between the two macrocycles. This is a clear indication of the tail-to-tail dimerization of two metallo-monoporphyrin complexes through a metal bridge, deviating from the head-to-head connection, i.e., sandwich complexes (Fig. 9). In the latter case the absorption bands would show much larger redshifts as well hyperchromicities, and the fluorescence would be much weaker, nearly disappear during the formation of bisporphyrin) as with the (parallel) head-to-tail dimer of the protonated porphyrin, $\left(\mathrm{H}_{4} \mathrm{TSPP}^{2-}\right)_{2}[42]$, and the typical OOP, sandwich-type bisporphyrins of mercury(II) ion: (parallel) head-to-tail $\mathrm{Hg}_{2}{ }_{2}$ (TSPP $)_{2}{ }^{8-}$ and typical head-to-head $\mathrm{Hg}_{3}{ }_{3}(\mathrm{TSPP})_{2}{ }^{6-}$ $[11,43]$.

Fig 9. Potential structures of 3:2 bisporphyrin: a) head-to-head or b) tail-to-tail. 
The tendency of the fluorescence quantum yields in Table 1 clearly shows that not the number of the unpaired electrons, but the size of the metal center is the key factor in this case. The lanthanide contraction as steric effect results in shorter out-of-plane distances, accordingly, less dome-distorted structures, which can cause the increase of the emission efficiency.

\subsection{Photochemistry}

In the lanthanide(III) porphyrins, the out-of-plane location of the metal center promotes two types of photochemical reactions, which are not characteristic for the in-plane complexes [3, 38]:

1) photoinduced demetalation (without any charge transfer), due to the lability of the complex; 2) oxidative degradation of the porphyrin ring, initialized by an irreversible, photochemical LMCT reaction. The reduction of the metal center increases its size (along with the decrease of its charge density), promoting the split of the coordinative bonds. The released metal ions of enhanced reduction potential can undergo further redox reactions, depending on their stability in the given medium. Thus, in aqueous solution, they can produce hydrogen from water. The oxidized porphyrin, an ionic radical, is a very strong base, which is immediately protonated, forming a long-lived and relatively strong oxidizer (in oxygen-free solution $\tau_{1 / 2}>>1 \mathrm{~ms}, \mathrm{E}_{1 / 2}>1 \mathrm{~V}$ ) [44]. In the absence of appropriate electron donors (such as alcohols or aldehydes) needed for the regeneration of the porphyrin ligand, an overall fourelectron oxidation takes place, leading to ring-opening and formation of a dioxo-tetrapyrrole derivative (bilindione) [3, 44]. This transformation (degradation) of the macrocyclic ligand is manifested in the disappearance of the Soret-band (Fig. 10).

Fig 10. Spectral changes in the range of Soret-bands during the photolysis at the Soretmaximum $(421 \mathrm{~nm})\left(9.2 \times 10^{-7} \mathrm{M} \mathrm{H}_{2} \mathrm{TSPP}^{4-}, 10^{-3} \mathrm{M} \mathrm{Ce}^{3+}\right.$, and $0.01 \mathrm{M}$ acetate, $\mathrm{pH} \approx 6, \mathrm{I}_{0}(421$ $\mathrm{nm})=1.88 \times 10^{-6} \mathrm{M}$ photon $\left./ \mathrm{s}, \ell=1 \mathrm{~cm}\right)$ at $0,4,10$, and $14 \mathrm{~min}$. Dashed line: after one day in dark. Adapted from refs $[38,40]$.

In the presence of acetate, i.e. during the photolysis of Ln(III) monoporphyrins, the photoinduced dissociation of the metal ion (without charge transfers) takes place only in 14$20 \%$ from the total photochemical reactions (Table 1). In the absence of acetate, the lanthanide(III) mono- and bisporphyrins exist in equilibrium in aqueous system, moreover free-base ligands may also remain because of the lower stability constants; hence, during the photolyses, they are simultaneously excited. Beside the photoredox degradations to the mentioned, open-chain photoproducts and dissociation to the free-base porphyrin, photoinduced transformation between the mono- and bisporphyrin complexes takes also place in these systems, affecting the equilibria between the complexes in photostationary state. Photoinduced dissociation in these systems proved to be reversible; the released free-base porphyrin converted to the lanthanide(III) complexes again within some days in the dark.

The overall quantum yields of the primary photochemical processes of these OOP complexes, i.e., the oxidation of the porphyrin ligand, are two orders of magnitude higher than those of the free-base or the in-plane metalloporphyrins $\left(\sim 10^{-6}\right.$ in $\left.[3,43]\right)$ as a consequence of the 
increased irreversibility of the photoinduced charge transfer from the ligand to the metal center in out-of-plane position.

The overall photochemical quantum yields monotonously increased with the concentration [9, $38,40]$. This phenomenon suggests that a bimolecular excited state (excimer formation), or dark reactions following the excitations, or the primary photochemical steps involve groundstate lanthanide(III) porphyrin complexes. This is in accordance with the observation that the oxidized ligand (radical) reacts further, through several redox steps, forming its final openchain bilindion derivative.

Only small differences appeared during the photolysis experiments of lanthanide(III) monoand bisporphyrin complexes. This phenomenon may confirm the special type of aggregation through the peripheral sulfonato substituents (tail-to-tail) because in the case of post-transition metal ions (head-to-head) the differences are much higher, mainly in the range of Q-bands [40].

The irradiation wavelength does not significantly influence the overall quantum yield as it was found for the cerium(III) porphyrins [38, 40]. However, the type of the photoproducts considerably depends on the excitation energy. During the photolysis at the Soret-band, a radical type intermediate can be detected (at $450 \mathrm{~nm}$ ), which disappears in dark (Fig. 11).

Fig 11. Spectral changes in the range of Soret- and Q-bands during the photolysis at the Soretmaximum (421 nm) at 0,3, 6, 10, and $14 \mathrm{~min}$ (the conditions are the same as at Fig 10). Dashed line: after one day in dark.. Adapted from refs [38, 40].

However, the photolysis at the Q-bands $(555 \mathrm{~nm})$ results in the formation of a new, stable photoproduct (Fig. 12), which was not observed earlier in the case of the porphyrin complexes of post-transition metal ions $[3,43]$. The absorption band at $590 \mathrm{~nm}$ may be assigned as a charge transfer in the complex between cerium(III) and the open-chain, dioxo-tetrapyrrole derivative (bilindion) $[3,44]$ formed in the irreversible oxidation of the ligand in LMCT process.

Fig 12.a) Spectral changes during the photolysis at the Q-maximum $(555 \mathrm{~nm})$ of a solution containing $1.75 \times 10^{-6} \mathrm{M} \mathrm{H}_{2} \mathrm{TSPP}^{4-}, 1.84 \times 10^{-3} \mathrm{M} \mathrm{Ce}^{3+}$, and $0.01 \mathrm{M}$ perchlorate $(\mathrm{pH} \approx 6$, $\mathrm{I}_{0}(556 \mathrm{~nm})=6.06 \times 10^{-6} \mathrm{M}$ photon $\left./ \mathrm{s}, \ell=1 \mathrm{~cm}\right)$ at $0,18,30$, and $62 \mathrm{~min}$. Dashed line: after one day in dark. b) Concentrations vs. irradiation time plots of the light-absorbing species. Adapted from ref [38].

On the basis of the lanthanide contraction, one can expect a monotonous decrease of the photochemical activities of the corresponding mono- and bisporphyrin complexes of metal centers with increasing atomic number, due to the decreasing out-of-plane distance, hindering the possibility of the photoinduced charge separation following LMCT. However, a small increase can be observed with these three lanthanide(III) ions, mainly for their bisporphyrin complexes (Table 1). This tendency suggests that the increasing out-of-plane distance causes an other, opposite effect too. That may be the hindrance of the electron transfer from the 
porphyrin ligand to the metal center, i.e. the step before the charge separation. Hence, a maximum value can be expected upon further increasing the atomic number, followed by a decreasing section of $\Phi$.

The overall photochemical quantum yield quasi-linearly increases with the concentration of ionic strength adjustors (acetate, perchlorate) due to the enhanced possibility of the charge separation following the photoinduced LMCT process, mainly in the case of bisporphyrins as it was observed for the neodymium(III) complexes [41]. Furthermore, the presence of acetate, as a potential axial ligand, hinders the photodissociation of the metal center from the monoporphyrin complex as a consequence of trans effect of the axially coordinated ligand, strengthening the M-N coordinative bonds.

\section{Summary and conclusions}

In this paper we summarized the results of investigation of some visible light-induced photophysical and photochemical features of water-soluble anionic and cationic metalloporphyrins. The main goal of these studies was to demonstrate the significant difference between the properties of the kinetically inert in-plane and the labile sitting-atop (SAT) or out-of-plane (OOP) complexes, due to their essential structural deviation.

As special representatives of the in-plane metalloporphyrins, cationic manganese(III), cobalt(III), and nickel(II) complexes were studied. The size of these metal centers are considerably smaller than the ligand cavity, hence they shrink the porphyrin ring, causing its distortion. Due to this effect, the UV-vis absorption spectra of these complexes deviate from the other (normal) in-plane metalloporphyrins and show similarities to those of the OOP types. The photochemical behavior of these hyper porphyrins, however, is characteristic of the kinetically inert complexes, the excited triplet state of which can be dynamically quenched with a suitable electron donor (TEOA) to reduce the metal center as in the case of the cationic $\mathrm{Mn}$ (III) and $\mathrm{Co}(\mathrm{III})$ porphyrins. Deviating from these complexes, the corresponding Ni(II) porphyrin forms an associate with this electron donor, preventing the dynamic quenching. But the long-lived triplet excited state of this associate is oxidatively quenched with methylviologen $\left(\mathrm{MV}^{2+}\right)$, realizing a one-step photoinduced electron transfer between the donor and acceptor. Thus, Ni(II)TMPyP ${ }^{4+}$ can be considered as a sensitizer in this system, while in the case of the manganese and cobalt porphyrins electron transmission from the reduced metal center toward the acceptor, also via outer-sphere mechanism, needs the absorption of another photon.

From the viewpoint of photoredox behavior, OOP complexes undergo inner-sphere LMCT reactions, instead of outer-sphere electron transfer. In these cases anionic porphyrin ligands are much more favorable than the positively charged ones. Lanthanide(III) ions as metal center of these complexes offered the possibility of tuning the out-of-plane position due to their contraction as a function of the atomic number. Besides the formation of mono- and bisporphyrins, they exhibit excitation wavelength-dependent photochemical behavior upon irradiation at the Soret- or Q-bands. 
All these results well demonstrate how the size of the metal center determines the structure and, thus, the photoinduced behavior of the porphyrins complexes, along with the substituents on the ligand.

\section{Acknowledgments}

This work was supported by the Hungarian Scientific Research Fund (OTKA, NN107310), the Hungarian Government and the European Union (TÁMOP-4.2.2.A-11/1/KONV-20120071), and the Austrian-Hungarian Action Foundation (90öu2).

\section{References}

1 .C. Mot, S.A. Syrbu, S.V. Makarov, G. Damian, R. Silaghi-Dumitrescu, Inorg. Chem. Commun. 18 (2012) 1-3.

2 T.S. Kurtikyan, V.A. Hayrapetyan, M.M. Mehrabyan, P.C. Ford, Inorg. Chem. 53 (2014) 11948-59.

3 O. Horváth, Z. Valicsek, G. Harrach, G. Lendvay, M.A. Fodor, Coord. Chem. Rev. 256 (2012) 1531-1545.

4 K. Ladomenou, M. Natali, E. Iengo, G. Charalampidis, F. Scandola, A.G. Coutsolelos, Coord. Chem. Rev. 304-305 (2015) 38-54.

5 K. T. Oppelt, E. Wöß, M. Stiftinger, W. Schöfberger, W. Buchberger, G. Knör, Inorg. Chem. 52 (2013) 11910-11922.

6 O. Horváth, R. Huszánk, Z. Valicsek, G. Lendvay, Coord. Chem. Rev. 250 (2006) 17921803.

7 Z. Valicsek, G. Lendvay, O. Horváth, J. Porph. Phthal. 13 (2009) 910-926.

8 X. Zhang, Y. Chen, Inorg. Chem. Commun. 39 (2014) 79-82.

9 Z. Valicsek, G. Eller, O. Horváth, Dalton Trans. 41 (2012) 13120-13131.

10 M. Gouterman, In Porphyris; Dolphin, D., Ed.; Academic Press: New York, 1978; Vol. III.

11 Z. Valicsek, O. Horváth, Microchem. J. 107 (2013) 47-62.

12 R.D. Shannon, Acta Crystallogr., Sect. A: Found. Crystallogr. 32 (1976) 751-767.

13 K M. Kadish, K.M. Smith, R. Guilard (Eds.) The porphyrin handbook: Inorganic, organometallic and coordination chemistry, Academic Press, London, 2000.

14 A. Harriman, G. Porter, J. Chem. Soc. Faraday Trans. II. 75 (1979) 1543-1552.

15 K. Kalyanasundaram, M. Neumann-Spallart, J. Phys. Chem. 86 (1982) 5163-5169.

16 M.A. Fodor, O. Horváth, L. Fodor, K. Vazdar, G. Grampp, A. Wankmüller, submitted

17 M.A. Fodor, O. Horváth, L. Fodor, G. Grampp, A. Wankmüller, Inorg. Chem. Commun. 50 (2014) 110-112. 
18 K. Kalyanasundaram, Inorg. Chem. 23 (1984) 2453-2459.

19 Z. Valicsek, O. Horváth, K. Patonay, J. Photoch. Photobio. A 226 (2011) 23-35.

20 X. He, Y. Zhou, L. Wang, T. Li, M. Zhang, T. Shen, Dyes and Pigments 39 (1998) 173182.

21 S.-M. Chen, J. Mol. Catal. A, 138 (1999) 1-13.

22 U. Sehlstedt, S.K. Kim, P. Carter, J. Goodisman, J.F. Vollano, B. Norden, J.C. Dabrowiak, Biochemistry 33 (1994) 417-426.

23 . I Kikaš, O.Horváth, I. Škorić, J. Mol. Struct. 1034 (2013) 62-68.

24 D. Vuk, I. Kikaš, K. Molčanov, O. Horváth, I. Škorić, J. Mol. Struct. 1063 (2014) 83-91.

25 N. Carnieri, A. Harriman, J. Photochem. 15 (1981) 341-346.

26 K. Takahashi, T. Komura, H. Imanaga, Bull. Chem. Soc. Jpn. 56 (1983) 3203-3207.

27 T. Watanabe, K. Honda, J. Phys. Chem. 86 (1982) 2617-2619.

28 R. F. Pasternack, Inorg. Chem. 15 (1976) 643-646.

29 R.F. Pasternack, E.G. Spiro, M. Teach, JRNC. 36 (1974) 599-606.

30 M.M. Major, M.A. Fodor, Z. Valicsek, L. Fodor, O. Horváth, G. Grampp, A. Wankmüller, submitted

31 J.W. Buchler, A. Decian, J. Fischer, M. Kihnbotulinski, H. Paulus, R. Weiss, J. Am. Chem. Soc. 108 (1986) 3652-3659.

32 G. Ricciardi, A. Rosa, E.J. Baerends, S.A.J. van Gisbergen, J. Am. Chem. Soc. 124 (2002) 12319-12334.

33 J. Jiang, M. Bao, L. Rintoul, D.P. Arnold, Coord. Chem. Rev. 250 (2006) 424-448.

34 V. Bulach, F. Sguerra, M.W. Hosseini, Coord. Chem. Rev. 256 (2012) 1468-1478.

35 H. He, Coord. Chem. Rev. 273 (2014) 87-99.

36 F.W. Oliver, C. Thomas, E. Hoffman, D. Hill, T.P.G. Sutter, P. Hambright, S. Haye, A.N. Thorpe, N. Quoc, A. Harriman, P. Neta, S. Mosseri, Inorg. Chim. Acta 186 (1991) 119-124.

37 H. Kunkely, A. Vogler, Inorg. Chem. Commun. 10 (2007) 479-481.

38 M. Imran, C. Szentgyörgyi, G. Eller, Z. Valicsek, O. Horváth, Inorg. Chem. Commun. 52 (2015) 60-63.

39 M.P. Kiss, M. Imran, C. Szentgyörgyi, Z. Valicsek, O. Horváth, Inorg. Chem. Commun. 48 (2014) 22-25.

40 M. Imran, C. Szentgyörgyi, Z. Valicsek, O. Horváth, RSC Advances, submitted 
41 M. Imran, Z. Valicsek, O. Horváth, RSC Advances, under preparation

42 D.L. Akins, S. Özcelik, H.R. Zhu, C. Guo, J. Phys. Chem. 100 (1996) 14390-14396.

43 Z. Valicsek, G. Lendvay, O. Horváth, J. Phys. Chem. B. 112 (2008) 14509-14524.

44 P. Neta, M. C. Richoux, A. Harriman, L. R. Milgrom, J.C.S. Faraday Trans. II. 82 (1986) 209-217. 


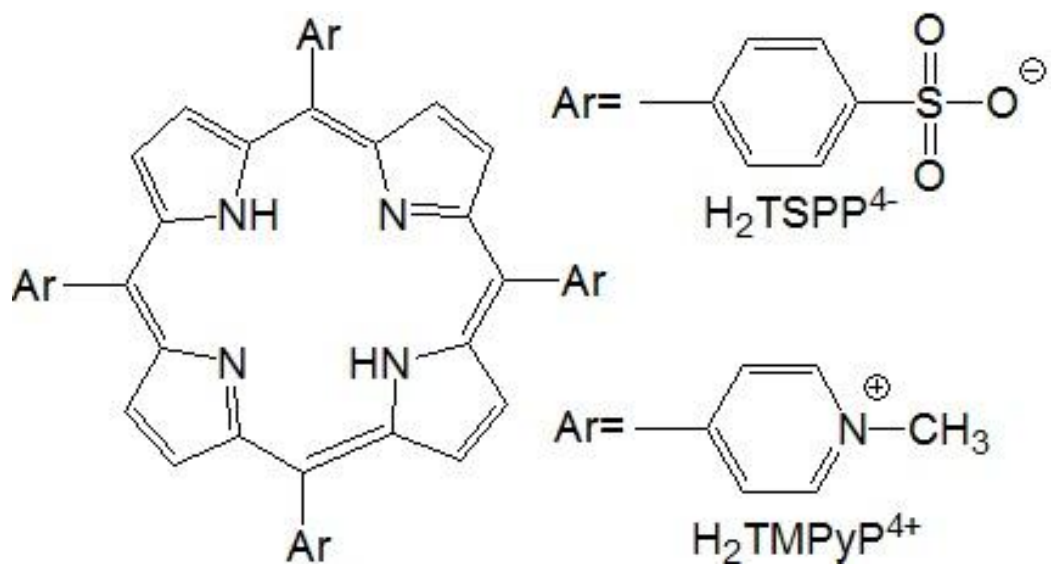

Fig. 1

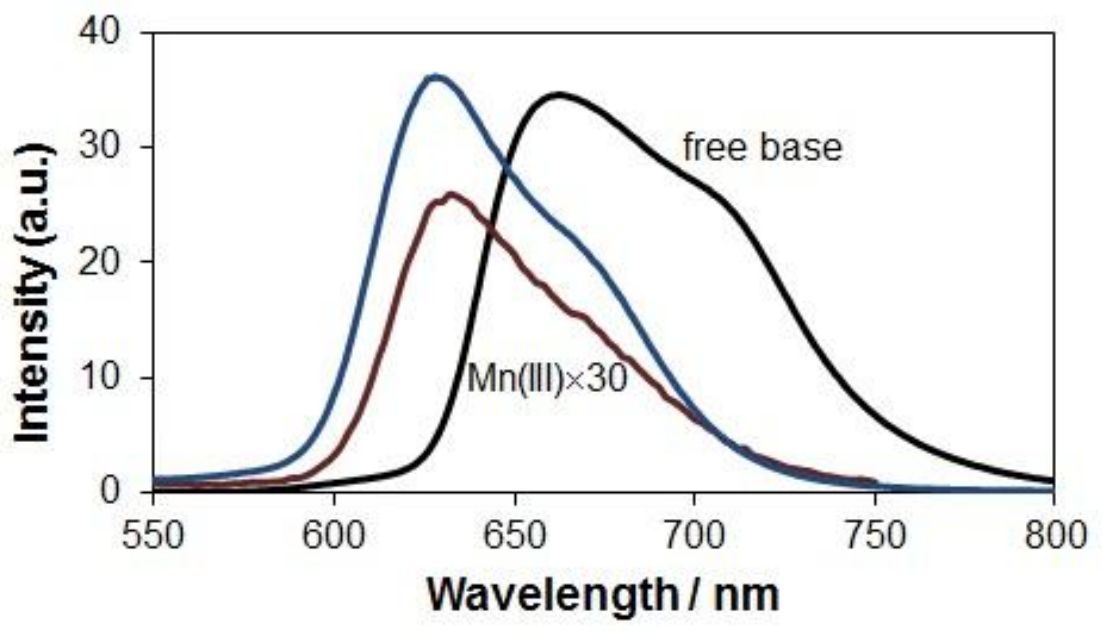

Fig. 2

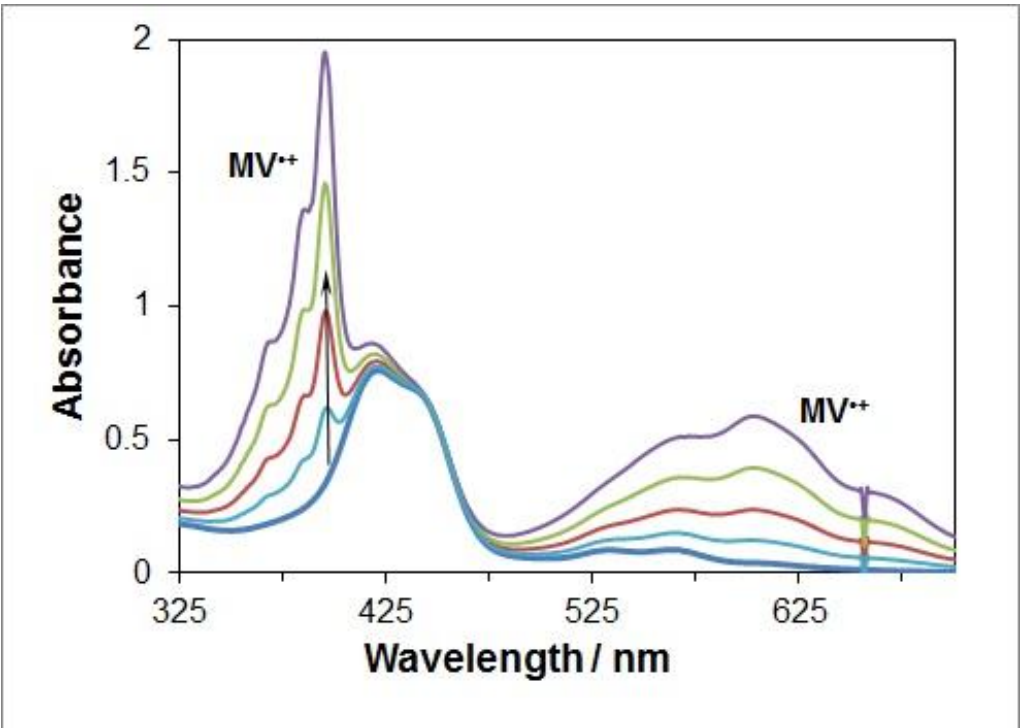

Fig. 3 


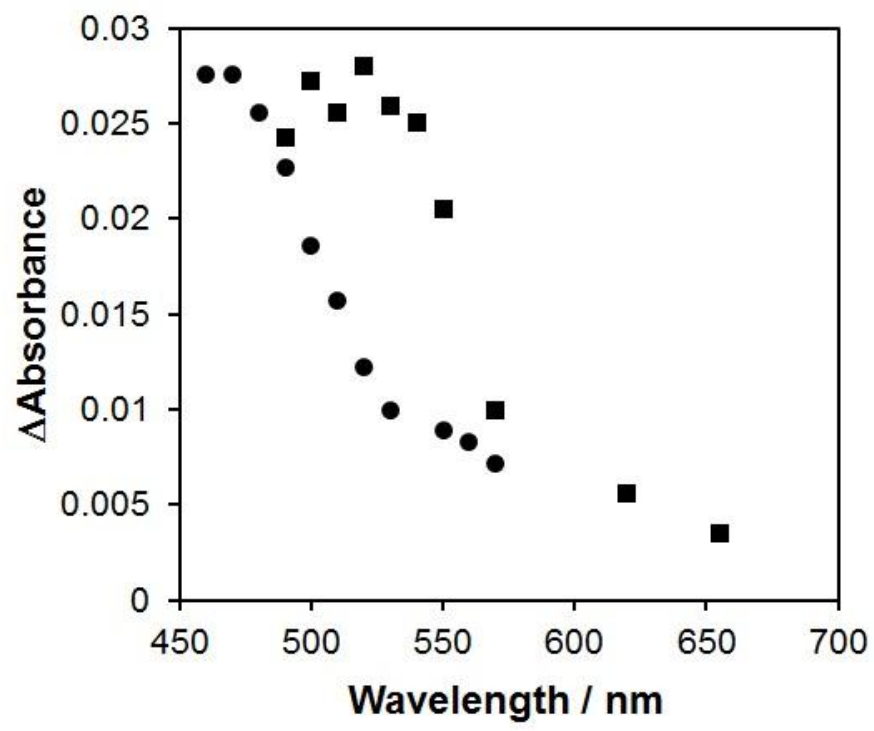

Fig. 4
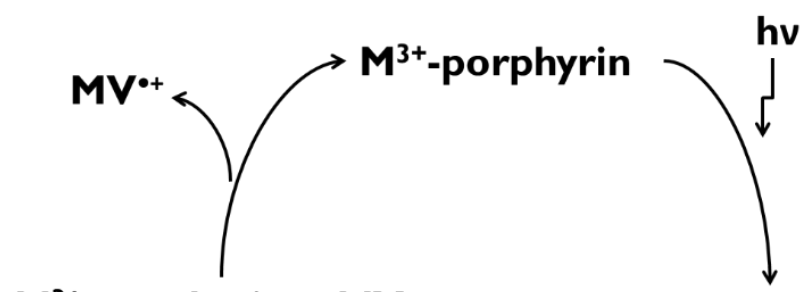

$\mathrm{M}^{3+}$-porphyrin + $\mathrm{MV}^{\cdot+}$

${ }^{*} \mathrm{M}^{3+}$-porphyrin triplet
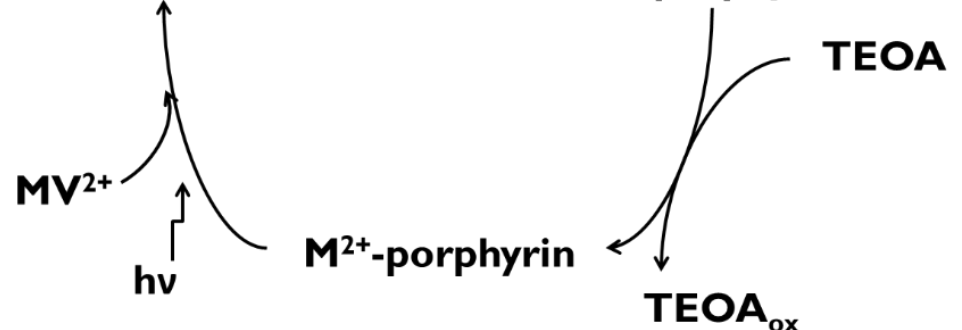

Scheme 1

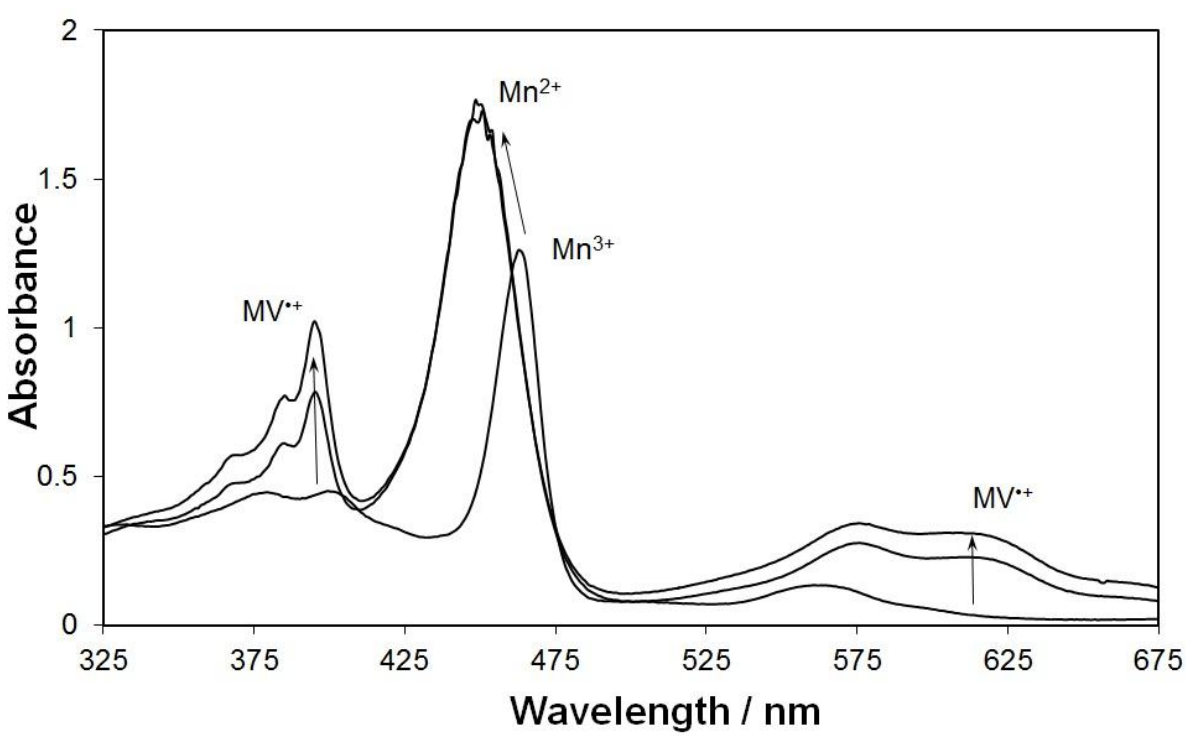

Fig. 5 


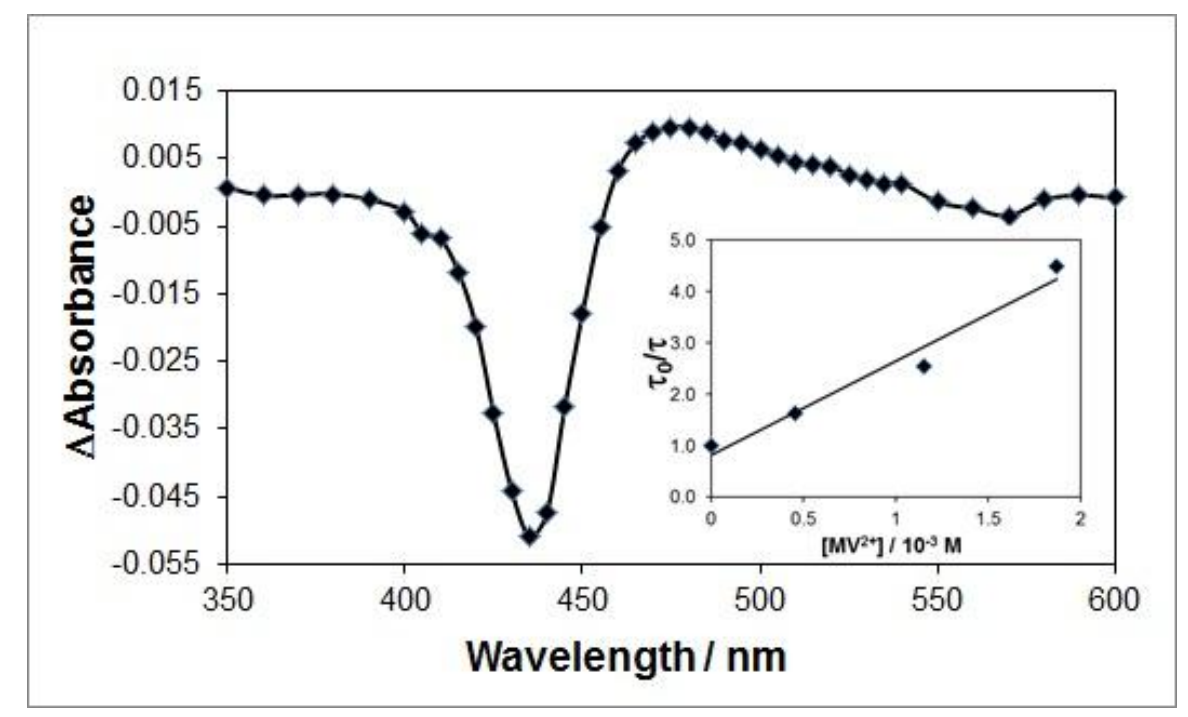

Fig. 6

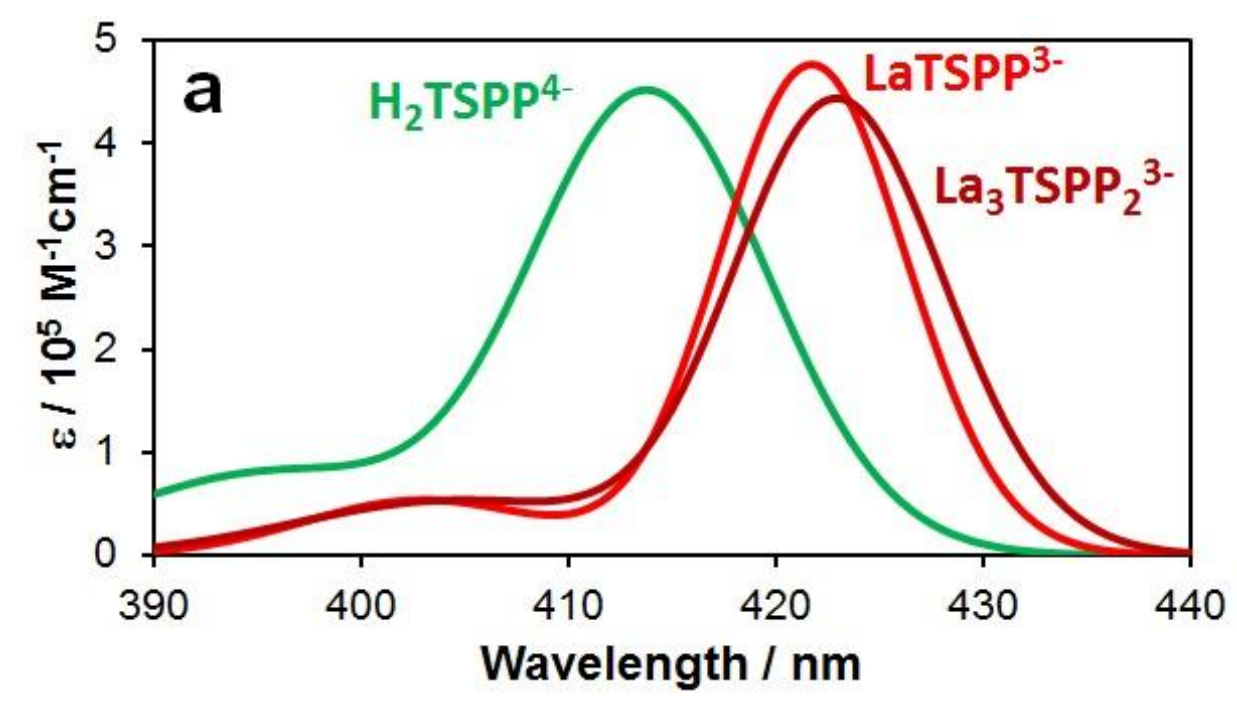

Fig. 7a

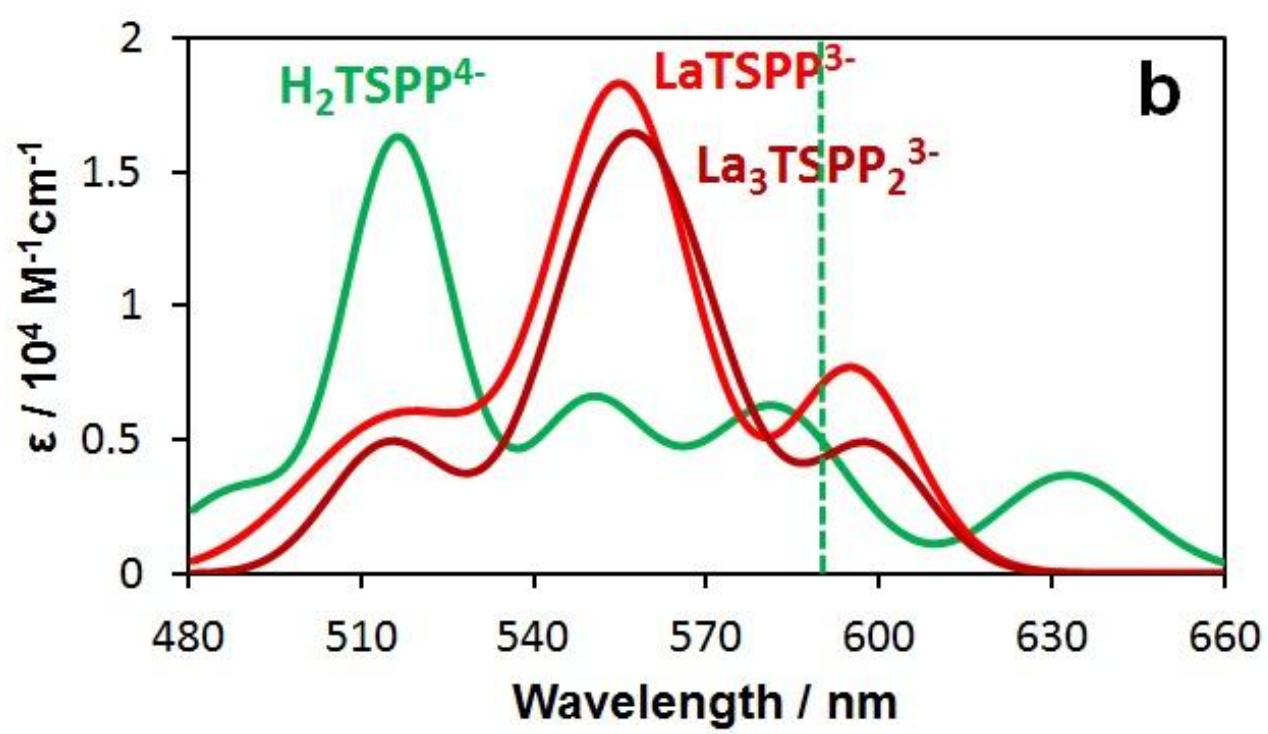

Fig. 7b 


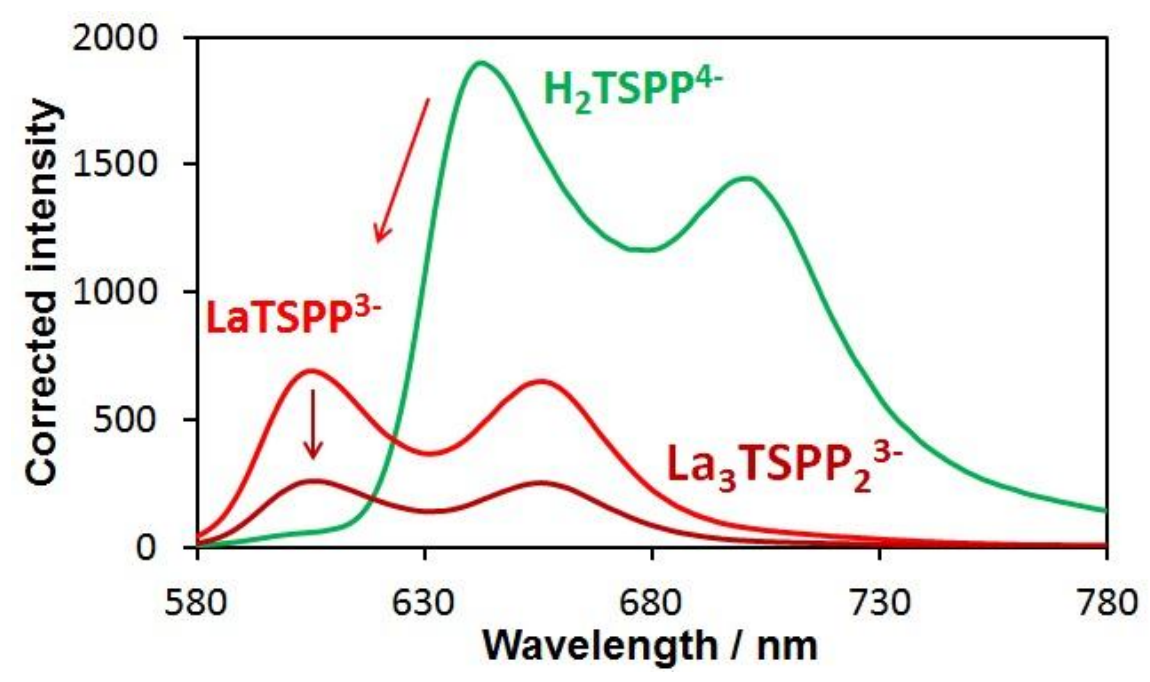

Fig. 8

a)

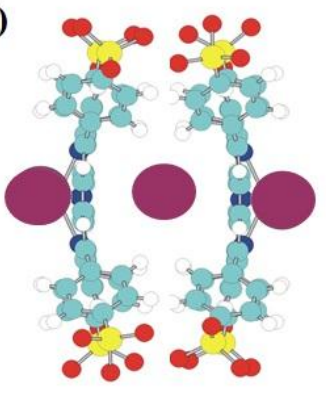

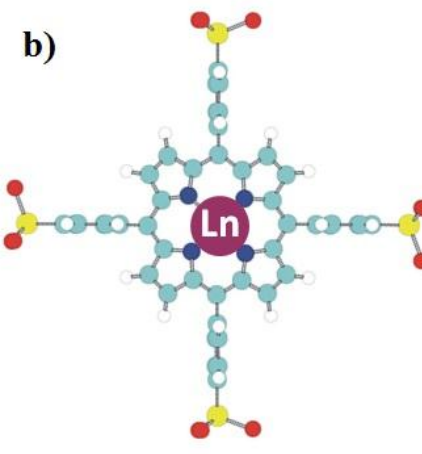

(In)

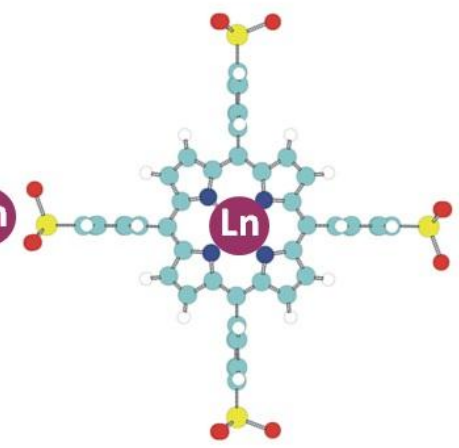

Fig. $9 a, b$

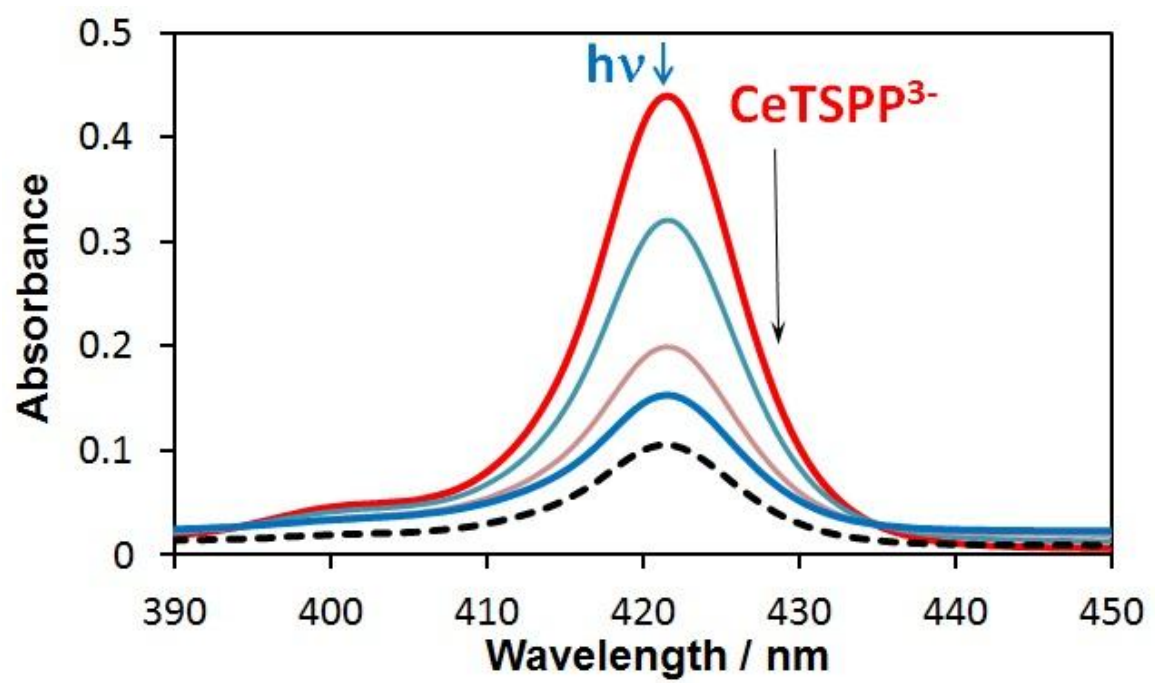

Fig. 10 


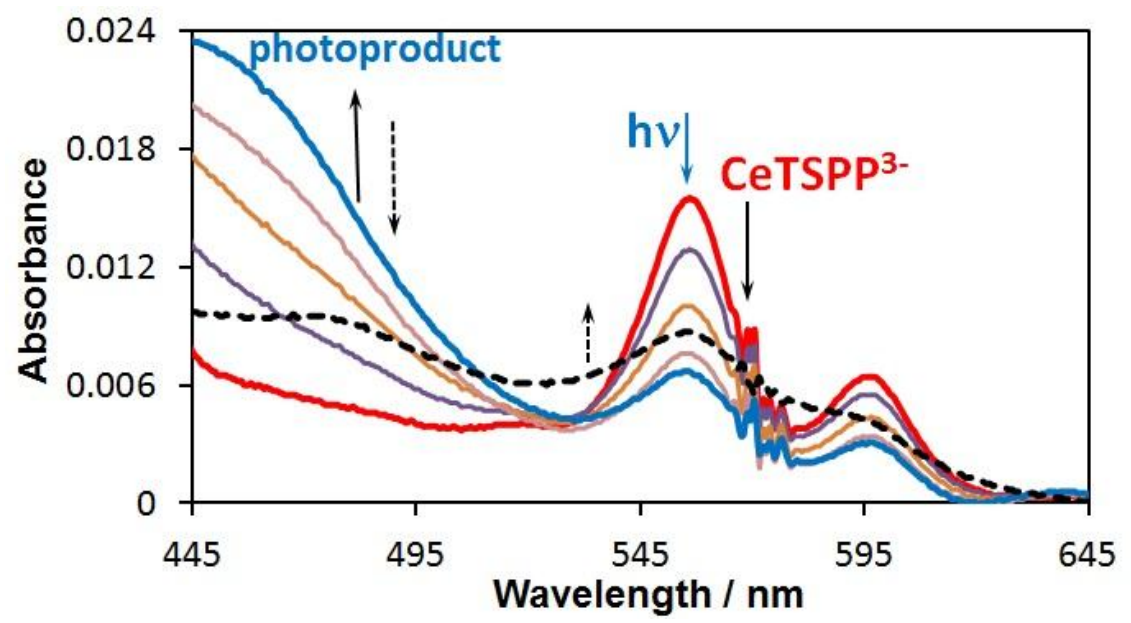

Fig. 11

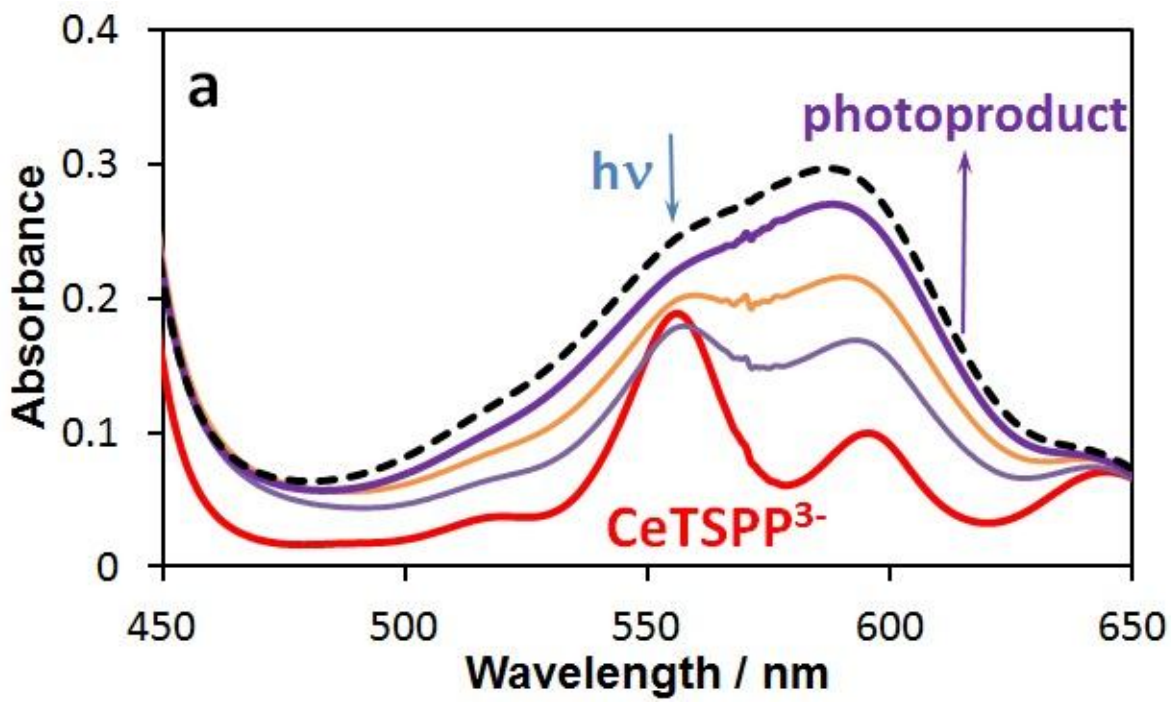

Fig. $12 \mathrm{a}$

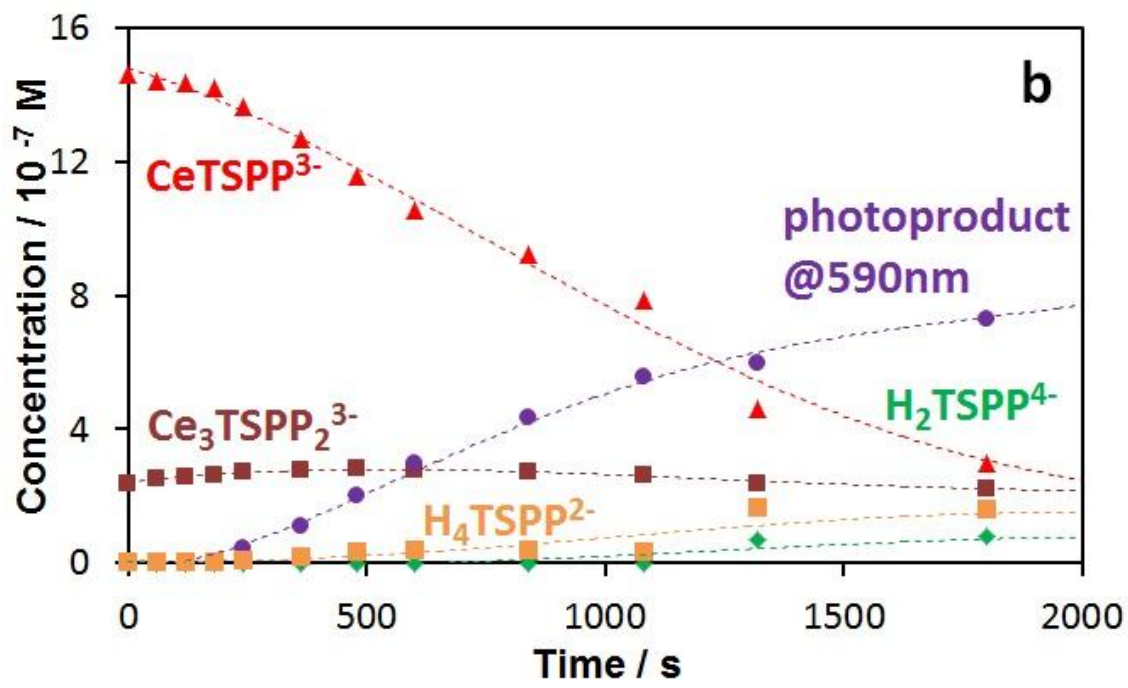

Fig. 12b 